\title{
Solvent-Free Powder Synthesis and MOF-CVD Thin Films of the Large-Pore Metal-Organic Framework MAF-6
}

\author{
Timothée Stassin, Ivo Stassen, João Marreiros, Alexander John Cruz, Rhea Verbeke, Min Tu, \\ Helge Reinsch, Marcel Dickmann, Werner Egger, Ivo F. J. Vankelecom, Dirk E. De Vos, \\ and Rob Ameloot*
}

\begin{abstract}
A simple solvent- and catalyst-free method is presented for the synthesis of the large-pore metal-organic framework (MOF) MAF-6 (RHO$\left.\mathrm{Zn}(\mathrm{eIm})_{2}\right)$ based on the reaction of $\mathrm{ZnO}$ with 2-ethylimidazole vapor at temperatures $\leq 100{ }^{\circ} \mathrm{C}$. By translating this method to a chemical vapor deposition (CVD) protocol, crystalline films of a large-pore material could be deposited for the first time entirely from the vapor phase. A combination of positron annihilation lifetime spectroscopy (PALS) and Kr physisorption measurements confirmed the porosity of these MOFCVD films and the size of the MAF-6 supercages (diameter $\sim 2 \mathrm{~nm}$ ), in close

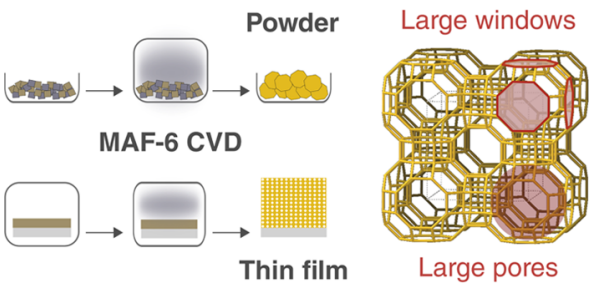
agreement with powder data and calculations. MAF-6 powders and films were further characterized by X-ray diffraction (XRD), thermogravimetric analysis (TGA), scanning electron microscopy (SEM), Fourier-transform infrared spectroscopy (FTIR), pair distribution function (PDF), and extended X-ray absorption fine structure (EXAFS). The exceptional uptake capacity of MAF-6 in comparison to ZIF-8 is demonstrated by vapor-phase loading of a molecule larger than the ZIF-8 windows.
\end{abstract}

\section{INTRODUCTION}

Metal-organic frameworks (MOFs) are microporous crystalline materials built up from metal ion nodes connected by multitopic organic linkers. ${ }^{1}$ Because of their record-breaking specific surface area (up to $7500 \mathrm{~m}^{2} \mathrm{~g}^{-1}$ ) and chemically tunable pore interior, ${ }^{2}$ MOFs have emerged as promising materials for both large-volume applications (e.g., adsorption, catalysis, gas storage $)^{3,4}$ and integrated, high-value applications (e.g., gas sensors, low- $k$ dielectrics, drug delivery). ${ }^{5}$

As for any material innovation, the processing conditions are critical for implementation in real-life applications. The following elements are typically desired for powder synthesis: high reaction yields, mild reaction conditions, cheap precursors such as metal oxides, no or recyclable nontoxic solvents. ${ }^{6,7}$ Several methods combine most of these criteria: (i) mechanochemical synthesis (dry milling) ${ }^{8}$ and its derivatives (ion-) and liquid-assisted grinding ((I)LAG), ${ }^{9}$ (ii) solvent-free reactions, ${ }^{10,11}$ and (iii) accelerated aging under high relative humidity and/or in the presence of a salt catalyst. ${ }^{12}$ These methods have been successful in the synthesis of microporous ZIF-8 $\left(\left[\mathrm{Zn}(\mathrm{mIm})_{2}\right]\right)$, also known as MAF-4, from $\mathrm{ZnO}$ and 2methylimidazole (HmIm)..$^{10,13,14}$

The production of MOFs as bulk powders recently led to commercial applications. ${ }^{15}$ Despite their great potential in other fields such as microelectronics, their implementation is impeded by the drawbacks of the existing thin film deposition methods. Indeed, traditional solvothermal protocols adapted from powder synthesis routes are incompatible with microfabrication (e.g., contamination by both chemicals and particles, corrosion). ${ }^{5,6}$ In contrast, other materials in microelectronic fabrication are typically deposited via chemical or physical vapor deposition (CVD/PVD). ${ }^{16}$

The first report on CVD of MOF films (MOF-CVD) demonstrated the deposition of ZIF-8 in two steps: (i) deposition of a $\mathrm{ZnO}$ precursor layer via an established process (e.g., atomic layer deposition, ALD) and (ii) MOF formation by reaction of the $\mathrm{ZnO}$ layer with $\mathrm{HmIm}$ vapor. ${ }^{17}$ Both steps of this process were recently automated and integrated into a cleanroom-ready single-chamber reactor. ${ }^{18}$ Unlike in the solvothermal conversion of metal oxide layers to MOFs, ${ }^{19}$ metal ions cannot be removed from the surface during MOFCVD, leading to pinhole-free and conformal films. Vapor-phase growth of MOFs is a rapidly expanding area, ${ }^{20}$ as illustrated by reports on the deposition of ZIF-67, ${ }^{21} \mathrm{CuBDC}^{22} \mathrm{CuCDC}^{22}$ HKUST- $1,{ }^{23}$ and a Zn-carboxylate-pyrazolate MOF-5 isotype structure. $^{24}$ Furthermore, related approaches have been developed such as CVD of amorphous precursors followed by postdeposition crystallization to form MOF-5, ${ }^{25}$ IRMOF$8,{ }^{26} \mathrm{UiO}-66,{ }^{27}$ and $\mathrm{UiO}-66-\mathrm{NH}_{2}{ }^{28}$ and the deposition of crystalline coordination compounds (e.g., MAF-252, ${ }^{29}$ $\mathrm{CaBDC},{ }^{30}$ and different $\mathrm{CuBDC}$ polymorphs $\left.{ }^{22,31}\right)$. Moreover, MOF-CVD has been successfully implemented in the 
fabrication of sensors, ${ }^{32}$ microsupercapacitors, ${ }^{33,34}$ and gas separation membranes. ${ }^{35,36}$

To date, however, no large-pore MOF material has been deposited by CVD. To expand the scope of the method, we selected the zeolitic imidazolate framework MAF-6 [Zn$\left.(\mathrm{eIm})_{2}\right]$, which consists of $\mathrm{Zn}^{2+}$ ions coordinated by 2ethylimidazolate (eIm) linkers. Although the composition of MAF-6 and ZIF-8 only differs by one methylene group in the substitution of the imidazolate linker, MAF- 6 crystallizes in the RHO instead of the SOD topology. The framework consists of truncated cuboctahedral supercages and octagonal prisms with the longest $\mathrm{Zn}-\mathrm{Zn}$ distances of 2.80 and $1.69 \mathrm{~nm}$, respectively. Each supercage is linked to six other supercages through prisms along the crystallographic axes. ${ }^{37,38}$ The additional methylene group of 2-ethylimidazole (HeIm) enhances the linker basicity ${ }^{39}$ and volatility, ${ }^{40}$ making it highly suitable for vapor-solid reaction with $\mathrm{ZnO}$.

Although MAF-6 has attractive properties such as large and highly hydrophobic pores, ${ }^{41}$ it is little studied in comparison to ZIF-8. This discrepancy stems from its difficult synthesis as a phase-pure material. MAF-6 was discovered by serendipity during the synthesis of mixed-linker ZIFs. ${ }^{37}$ Only a few crystals were isolated, preventing characterization beyond structure elucidation. Later, a reproducible ILAG synthesis of MAF-6 from $\mathrm{ZnO} / \mathrm{HeIm} /\left(\mathrm{NH}_{4}\right)_{2} \mathrm{SO}_{4} /$ solvent mixtures was published. $^{42}$ This study attributed the difficult solvothermal synthesis of MAF-6 to its metastable nature. Indeed, timedependent experiments revealed that gradually denser topologies are formed in the $\mathrm{Zn}(\mathrm{eIm})_{2}$ system over the course of the grinding reaction: from $\mathrm{RHO}-\mathrm{Zn}(\mathrm{eIm})_{2}$ (MAF-6) over ANA-Zn(eIm) $)_{2}$ (MAF-5, ZIF-14) to QTZ-Zn(eIm) $)_{2}$ (MAF32). ${ }^{43}$

Further developments have since been made in the preparation of MAF-6. The first gram-scale synthesis and experimental confirmation of porosity in MAF- 6 were obtained by accelerated aging using nonammonium sulfate catalysts. ${ }^{13}$ HeIm was proven to act as a space-filling or templating agent. Therefore, full $\mathrm{ZnO}$ conversion could only be reached in the presence of excess HeIm. The salt catalyst can only be removed by solvent washing to obtain an activated MAF-6 material. A solvothermal synthesis yielding pure MAF-6 followed, after careful optimization of apolar additives (e.g., cyclohexane) and the order of mixing the different solutions. ${ }^{41}$ Solvothermal protocols were also reported for the RHO-, ANA-, and QTZ-Co(eIm) $)_{2}$ analogues, again making use of an additive thought to serve as a template. ${ }^{44}$ Recently, QTZ$\mathrm{Fe}(\mathrm{eIm})_{2}$ was obtained by a solvent-free route as well. ${ }^{45}$ Despite these advances in materials synthesis, an entirely solvent-free protocol for MAF-6 is still missing. This work aims at filling this gap.

Here, we report the first powder synthesis and film deposition of MAF-6 entirely from the vapor phase, i.e., without any solvent in either the synthesis or the activation stage (Figure 1).

\section{RESULTS AND DISCUSSION}

MAF-6 CVD Powders. CVD MAF-6 powder is obtained by heating a mixture of $\mathrm{ZnO}$ and HeIm (Figure 2a). While solid and vaporized HeIm is stable, molten HeIm ( $\mathrm{mp} \sim 83$ ${ }^{\circ} \mathrm{C}$ ) can degrade via oligomerization. ${ }^{46}$ To avoid this issue while ensuring a short synthesis time and a high conversion, the reaction temperature was set at $80{ }^{\circ} \mathrm{C}$ (Figure S2.1). Powder X-ray diffraction (PXRD) data confirms the formation a
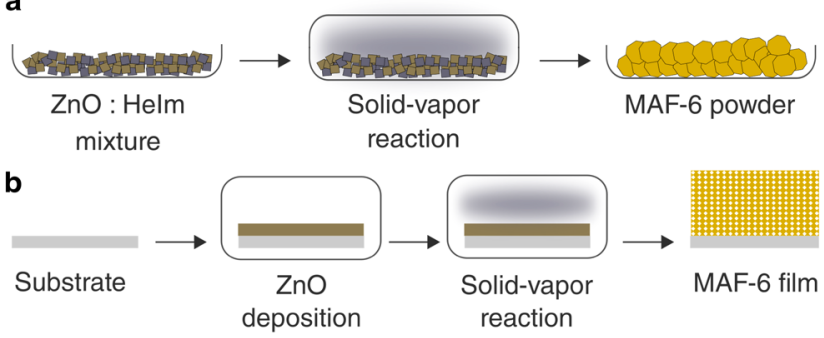

C
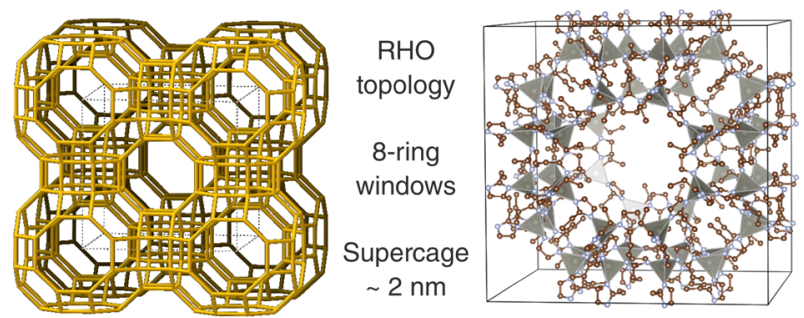

Figure 1. Large-pore MAF-6 from the reaction between $\mathrm{ZnO}$ and 2ethylimidazole vapor. (a) Schematic representation of the CVD powder synthesis. (b) Schematic representation of the film CVD. (c) MAF-6 RHO topology, showing the supercages connected through octagonal prisms and (d) cubic unit cell of MAF-6.

of MAF-6, together with leftover $\mathrm{ZnO}$ (Figure S3.1). When starting from $25 \mathrm{~nm} \mathrm{ZnO}$ particles, $8 \mathrm{wt} \% \mathrm{ZnO}$ remains, as determined by thermogravimetric analysis (TGA) (Figure $2 b$ ). This value was confirmed by quantitative ${ }^{1} \mathrm{H}$ NMR spectroscopy after digestion of the sample ( 9 wt \% $\mathrm{ZnO}$, Supporting Information (SI), Section S4). As for the material prepared from solution, ${ }^{41} \mathrm{CVD}$ MAF-6 decomposes at $\sim 400{ }^{\circ} \mathrm{C}$ in air and is remarkably stable for a large-pore MOF. ${ }^{47}$ Scanning electron microscopy (SEM) shows aggregates of rhombic dodecahedra nanocrystals $\sim 200 \mathrm{~nm}$ in diameter (Figure S5.1). The larger size of the nanocrystals, when compared to the initial $\mathrm{ZnO}$ nanoparticles, is the result of (i) the volume expansion during the conversion from dense $\mathrm{ZnO}$ to porous MOF (SI, Section S6) and (ii) crystallite ripening. Similar volume expansion was also observed for ZIF-8 powder synthesized from $\mathrm{ZnO}$ under dry milling conditions. ${ }^{14}$

The porosity of CVD MAF- 6 was evaluated with $\mathrm{N}_{2}$ physisorption at $-196{ }^{\circ} \mathrm{C}$, taking into account the fraction of residual, dense $\mathrm{ZnO}$ (Figure $2 \mathrm{~d}$ ). As expected, the isotherm is of Type $\mathrm{I}(\mathrm{b})$, characteristic of wide micropores or narrow mesopores $(d<\sim 2.5 \mathrm{~nm}){ }^{48}$ The Brunauer-Emmett-Teller (BET) surface area $\left(1485 \mathrm{~m}^{2} \mathrm{~g}^{-1}\right)$ lies in between the experimental value reported for solvothermal MAF-6 $\left(1343 \mathrm{~m}^{2}\right.$ $\mathrm{g}^{-1}$ ) and the value calculated for the refined crystal structure (1571 $\mathrm{m}^{2} \mathrm{~g}^{-1}$, Table S7.1). ${ }^{41}$ Additionally, the pore size distribution extracted from the physisorption data using a density functional theory model $\left(\mathrm{N}_{2}\right.$ on oxide surface, cylindrical pores) confirms the large size of the supercage $(1.85 \mathrm{~nm})$ (Figure 2d, inset).

Intensity changes in the low-angle diffraction peaks of assynthesized CVD MAF- 6 upon activation indicate the presence of linker molecules filling the pores (Figure S8.1), ${ }^{49-51}$ as for ZIF-8 prepared under similar conditions, and MAF-6 synthesized by accelerated aging with salt catalysts. ${ }^{13,17}$ CVD MAF- 6 can be activated through simple sublimation of excess HeIm adsorbed on the surface and in the pores, thereby achieving an entirely solvent- and waste-free process. 

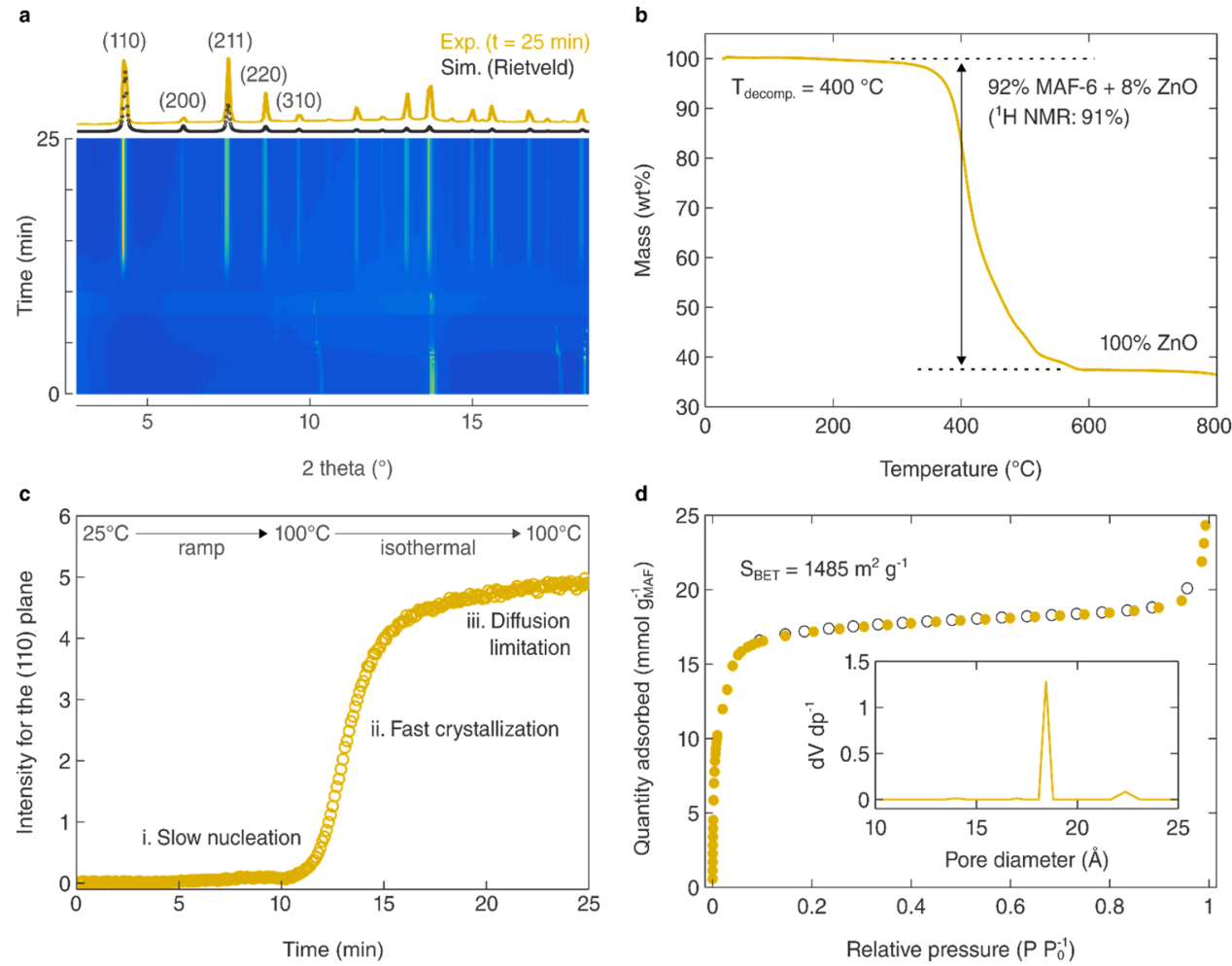

Figure 2. MAF-6 powder synthesis and characterization. (a) In situ PXRD data viewed down the intensity axis showing the transformation of crystalline phases in a 1:4 mixture of crystalline $\mathrm{ZnO}$ and HeIm powder heated from 25 to $100{ }^{\circ} \mathrm{C}(t=11 \mathrm{~min})$. Color scale from blue (low intensity) to yellow (high intensity). The final diffraction pattern ( $t=25 \mathrm{~min})$ is plotted on top (yellow), along with the pattern simulated from the refined crystal structure (black). (b) TG curve measured in air showing the decomposition of MAF-6 to $\mathrm{ZnO}$ in a single step at $\sim 400{ }^{\circ} \mathrm{C}$. (c) MAF6 formation plotted as the diffracted intensity of the (100) plane during the in situ PXRD measurement. (d) $\mathrm{N}_{2}$ adsorption (filled dots) and desorption (empty dots) isotherms measured at $-196^{\circ} \mathrm{C}(77 \mathrm{~K})$. Inset: pore size distribution extracted from the adsorption branch using a density functional theory model.
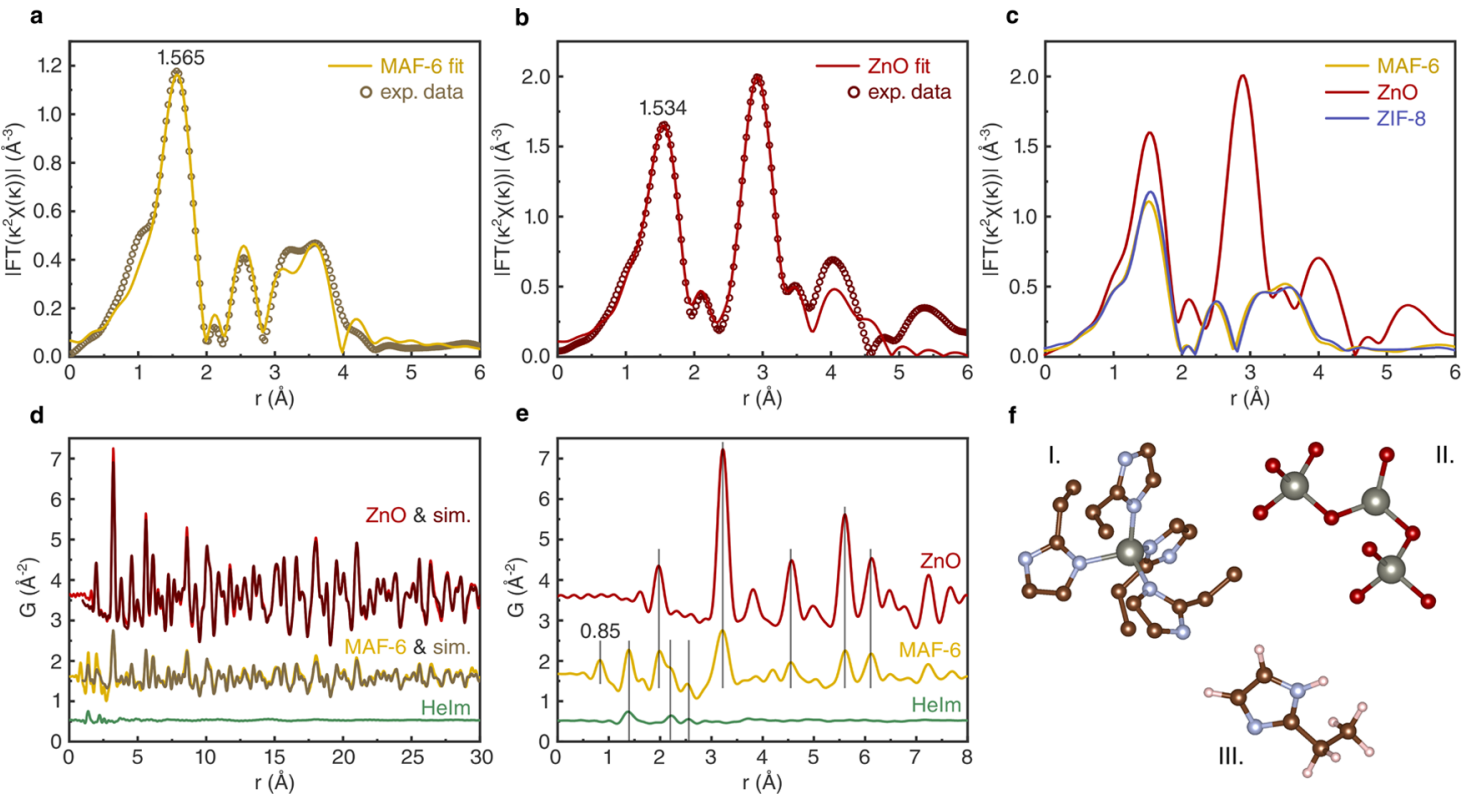

Figure 3. MAF-6 powder characterization by EXAFS and total scattering measurements. (a) MAF-6 FT-EXAFS spectrum (dots) and fit (yellow line). (b) ZnO FT-EXAFS spectrum (dots) and fit (red). (c) Comparison of FT-EXAFS spectra of MAF-6 (yellow), ZnO (red), and ZIF-8 (blue). (d) Pair distribution function (PDF) of MAF-6 (yellow), $\mathrm{ZnO}$ (red), and HeIm (green) compared to that simulated from refined structural models. (e) Low- $r$ region of the PDFs with common peaks indicated by vertical bars. (f) Models used for simulations: (I) Zn tetrahedrally coordinated by four eIm ligands, (II) $\mathrm{ZnO}$, (III) HeIm. The corresponding elements are carbon (brown), nitrogen (blue), zinc (silver), oxygen (red), and hydrogen (pink). 

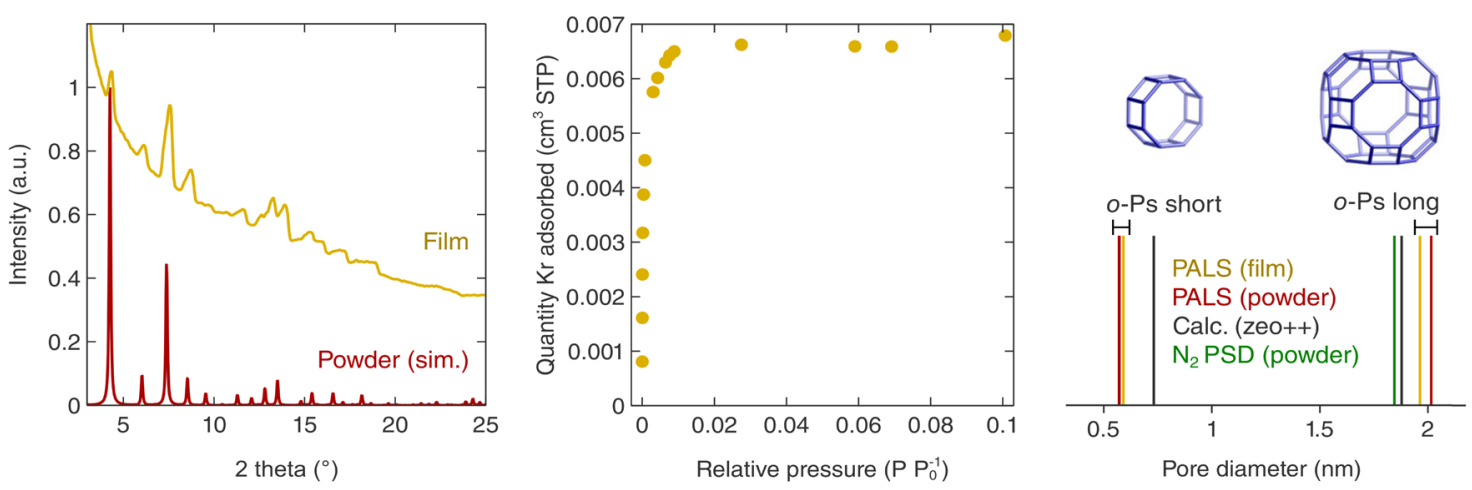

d

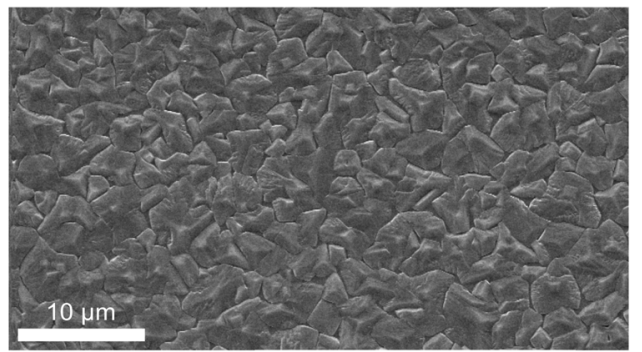

e
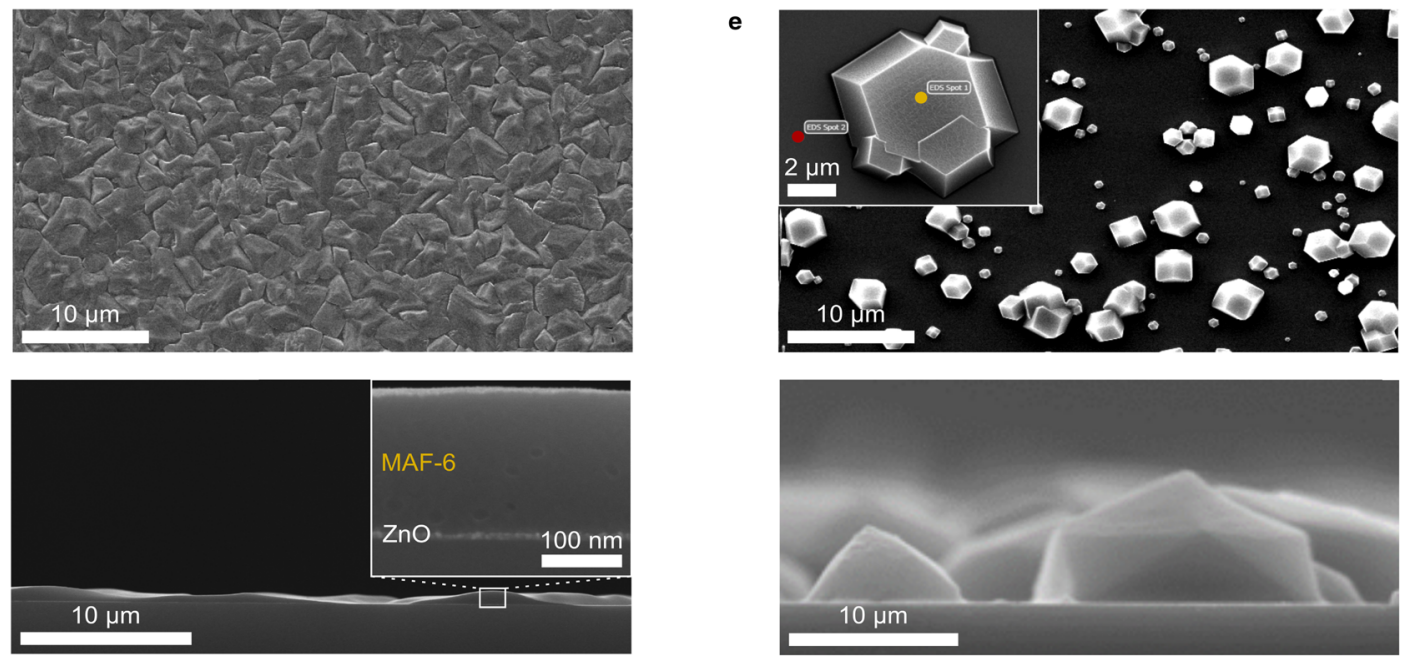

Figure 4. MAF-6 film deposition and characterization. (a) Synchrotron GIXRD pattern of a MAF-6 film (yellow) plotted against the simulated powder pattern for the refined crystal structure (red). (b) Kr adsorption isotherm measured at $-196{ }^{\circ} \mathrm{C}(77 \mathrm{~K})$ on a MAF-6 film. (c) Summary plot of MAF-6 pore size investigation: short and long o-Ps lifetimes obtained from PALS measurements on a MAF-6 film (yellow) and powder pellet (red) at $1.0 \mathrm{keV}$ positron implantation energy, the maximum of the pore size distribution from $\mathrm{N}_{2}$ physisorption on MAF- 6 powder (green), and the calculated size of the largest sphere passing the octagonal prisms and of the largest sphere fitting in the supercage of the MAF- 6 crystal structure (gray). The two building units of the MAF-6 RHO topology (octagonal prism and supercage) are depicted as well. (d) Top-view (top) and cross-sectional (bottom) SEM images of a nearly continuous MAF-6 film. Inset: cross-sectional SEM image at a higher magnification revealing the presence of residual $\mathrm{ZnO}$ underneath the MAF-6 film. (e) Top-view (top) and cross-sectional (bottom) SEM images of scattered MAF-6 crystals on a surface. Inset: location of the two energy-dispersive X-ray spectroscopy (EDS) measurements on (yellow) and near (red) a MAF-6 crystallite, where $\mathrm{Zn}$ is present and absent, respectively.

In situ PXRD revealed that MAF-6 forms as the first and only crystalline product during CVD (Figure 2a). In contrast to mechanochemical syntheses, ${ }^{42}$ the denser ANA-Zn(eIm) and QTZ-Zn $(\mathrm{eIm})_{2}$ phases are not observed, even at extended reaction times. The intensity of the main (110) reflection displays a sigmoidal evolution (Figure 2c), as observed for the CVD of ZIF-8 powder and films. ${ }^{17,18}$ This sigmoidal shape can be attributed to three consecutive growth stages: (i) reaction of $\mathrm{ZnO}$ and HeIm followed by slow nucleation, (ii) rapid crystallization, and (iii) increasingly slow diffusion of the HeIm linker through the formed MAF-6 layer to reach residual underlying $\mathrm{ZnO}$. Therefore, an incomplete conversion is observed even after extended reaction times $(24 \mathrm{~h})$. Starting from micron- instead of nanosized particles, a higher residual $\mathrm{ZnO}$ content of 37 wt \% was measured by TGA (32\% by Rietveld refinement). As observed for ZIF-8 formed by dry milling, ${ }^{14}$ larger $\mathrm{ZnO}$ particles lead to a lower degree of conversion.

To probe changes in the local environment of the $\mathrm{Zn}^{2+}$ ions upon conversion, MAF-6 powders, $\mathrm{ZnO}$ precursor, and commercial ZIF-8 (Basolite Z1200) were analyzed by Zn kedge extended X-ray absorption fine structure (EXAFS) (Figure 3). ${ }^{52}$ The Fourier-transform (FT) EXAFS spectra for $\mathrm{ZnO}$ and MAF- 6 were fitted with EXAFS functions calculated from the reported structure of wurtzite and the refined structure of MAF- 6 in the range $1 \AA<r<6 \AA$, respectively (Figure 3a,b). The fits corresponded well with the experimental data $(R$-factor $<0.025)$ as well as with previous reports on $\mathrm{ZnO} .{ }^{53,54}$ The identical FT-EXAFS spectra of MAF6 and commercial ZIF-8 (Figure 3c) evidence similar Zn geometrical (tetrahedral coordination) and chemical (imidazolate ligands) environments of both frameworks, yet differing in topology (Figure $3 \mathrm{f}-\mathrm{I}$ ). The data show an intense low- $r$ peak in all samples, corresponding to the first coordination shell of $\mathrm{Zn}^{2+}(\mathrm{Zn}-\mathrm{O}$ and $\mathrm{Zn}-\mathrm{N}$ bonds, Figure 3c). The position of this peak increases from $1.534 \AA(\mathrm{ZnO})$ to $1.565 \AA$ (MAF-6), in line with the replacement of oxygen with nitrogen resulting in slightly longer electron scattering paths. The drop in peak area and intensity further highlights the reduced electron density upon transition from $\mathrm{ZnO}$ to MAF-6. At 

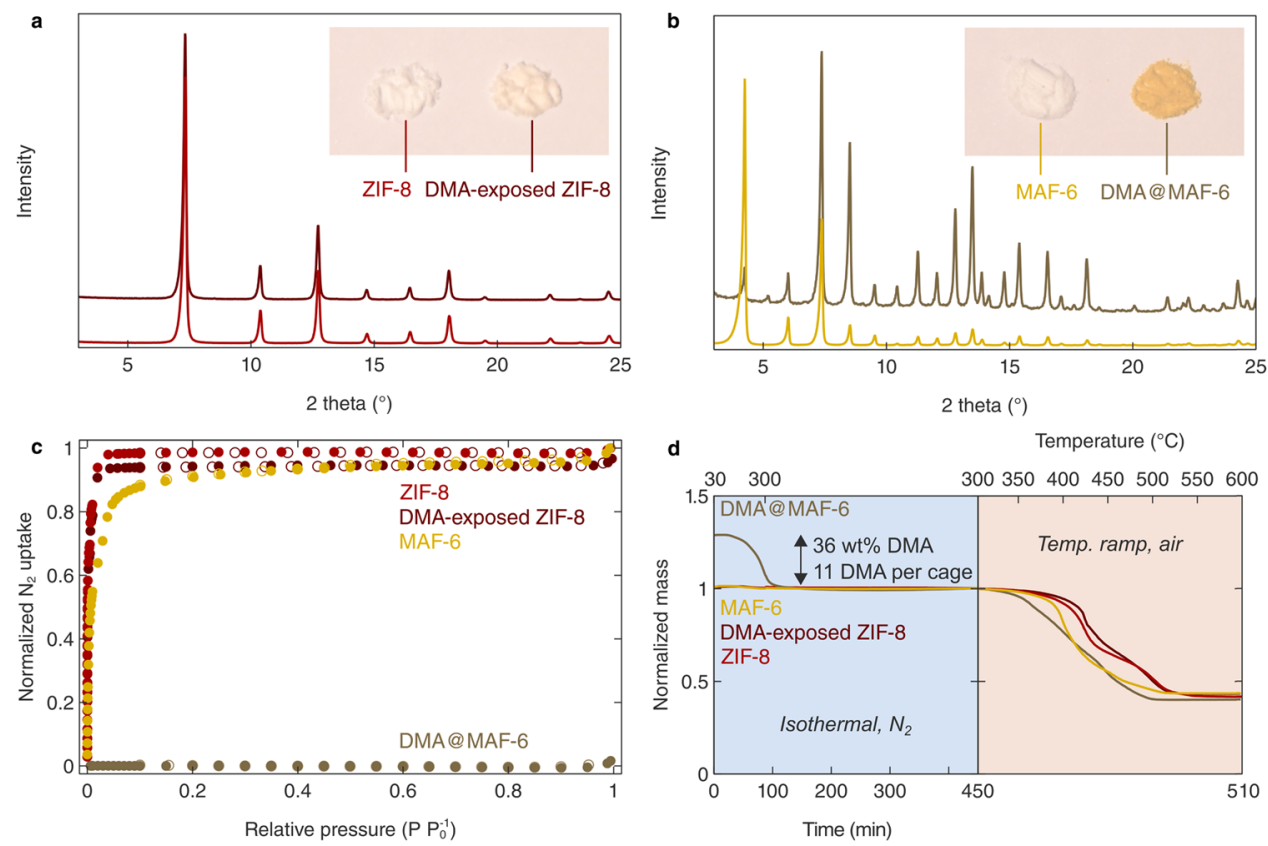

Figure 5. Size exclusion and adsorption of the large 9,10-dimethylanthracene (DMA) dye molecule in ZIF-8 and MAF-6. (a) PXRD patterns of ZIF-8 before and after DMA loading. Inset: images of ZIF-8 powder before and after DMA loading. (b) PXRD patterns of MAF-6 before and after DMA loading. Inset: images of MAF-6 powder before and after DMA loading. (c) $\mathrm{N}_{2}$ adsorption (filled dots) and desorption isotherms (empty dots) measured at $-196^{\circ} \mathrm{C}$ showing the complete loss of porosity in MAF- 6 after DMA loading while the porosity in ZIF- 8 remains unchanged. The isotherms are normalized to the maximum uptake of the nonloaded material (at $P P_{0}{ }^{-1}=0.98$ ). (d) Temperature-programed desorption consisting of two segments: (left) temperature ramp $\left(3{ }^{\circ} \mathrm{C} \mathrm{min}{ }^{-1}\right)$ and isothermal step at $300{ }^{\circ} \mathrm{C}$ under inert atmosphere showing DMA desorption only from DMA@MAF-6 followed by (right) temperature ramp $\left(5^{\circ} \mathrm{C} \mathrm{min}^{-1}\right)$ to $600{ }^{\circ} \mathrm{C}$ under air atmosphere showing similar decomposition to $\mathrm{ZnO}$ of the loaded and nonloaded material. The curves are normalized to the mass at the start of the second segment (time $=450$ min, temperature $=300{ }^{\circ} \mathrm{C}$ ).

higher $r$-values, the MAF- 6 spectrum diverges from the oxide spectrum, becoming featureless above $4.2 \AA$ as a result of the low density of the MOF. At a low degree of conversion, intermediate coordination between the precursor and the framework is observed (Figure S9.1). These results indicate that during the formation of CVD MAF-6, the metal cations retain their tetrahedral coordination, contrary to what has been observed in the solvothermal synthesis of ZIF-8.

Complementary total scattering measurements were performed during in situ ZnO-to-MAF-6 transformation, which resulted in intense scattering pattern changes and reached near-complete conversion ( $92 \%$ ) (Figure S10.1). ${ }^{55}$ Pair distribution functions (PDFs) were calculated for MAF- $6_{92} \%$, $\mathrm{HeIm}$, and $\mathrm{ZnO}$ in the range $0<r<30 \AA$. In contrast to $\mathrm{ZnO}$ and MAF-6, HeIm lacks well-defined long-range order and its PDF becomes featureless at $r \geq 4 \AA$ (Figure $3 \mathrm{~d}, \mathrm{e}$ ). As expected, the interatomic distances characteristic of $(\mathrm{H}) \mathrm{eIm}(1.38,2.22$, and $2.55 \AA$ ) and of $\mathrm{ZnO}(1.98,3.22,4.47,5.61$, and $6.13 \AA$ ) are observed in the PDF of MAF- $6_{92}$. Triple phase refinement of the MAF-6 PDFs was performed in PDFgui ${ }^{56}$ in the $r$-range 1-30 A, using $\mathrm{ZnO}$ and MAF-6 structure files and a HeIm structural model (Figure 3f-III). The refinement confirms the coexistence of MAF-6 together with residual $\mathrm{ZnO}$ and HeIm $\left(r_{\mathrm{w}}=0.343\right)$. The small mismatch between data and fit at $r<5$ $\AA$ is possibly due to HeIm adsorbed in the framework. The unknown peak at $0.85 \AA$ present in both in and ex situ measurements might be due to the presence of in situ generated water. ${ }^{18,57}$

MAF-6 CVD Thin Films. The CVD of MAF-6 can be translated to thin films through the exposure of thin (1-10 $\mathrm{nm}$ ) $\mathrm{ZnO}$ layers to HeIm vapor. Crystalline MAF-6 films are obtained as confirmed by grazing incidence X-ray diffraction (GIXRD) (Figure 4a). Infrared measurements also show a good agreement between MAF-6 powder and films (Figure S11.1). The evaluation of porosity in these thin films was tackled via a combination of high-sensitivity $\mathrm{Kr}$ physisorption and positron annihilation lifetime spectroscopy (PALS) measurements. $\mathrm{Kr}$ physisorption at $-196{ }^{\circ} \mathrm{C}(77 \mathrm{~K})$ yielded a type $\mathrm{I}(\mathrm{b})$ isotherm, thereby verifying the accessible porosity of the film (Figure 4b). PALS probes the presence and size of free-volume elements in a material. It measures the pick-off lifetime of the ortho-positronium (o-Ps) formed upon positron implantation. ${ }^{58}$ The mean positron implantation depth in the material depends on the positron implantation energy and the material density. A MAF-6 film (calculated crystallographic density $=0.77 \mathrm{~g} \mathrm{~cm}^{-3}$ ) was investigated at $1.0 \mathrm{keV}$, thus at a mean depth of $40 \mathrm{~nm}$ (Figure S12.1). Two o-Ps lifetimes were found, corresponding to spherical cages with a diameter of 0.59 and $1.96 \mathrm{~nm} .{ }^{59,60}$ These match, respectively, the size of the largest sphere that passes through the octagonal prisms $(0.73$ $\mathrm{nm})$ and the one fitting in the supercage $(1.88 \mathrm{~nm})$, as calculated using Zeo++ (Figure 4c). ${ }^{61}$ Similar lifetimes were observed during PALS measurements deeper in the film (1.5 $\mathrm{keV}, 78 \mathrm{~nm}$ mean depth) and on a CVD MAF-6 powder pellet (Table S12.1). These results are in agreement with the $\mathrm{N}_{2}$ physisorption data where a supercage diameter of $1.85 \mathrm{~nm}$ was obtained from the pore size distribution (Figure 2d).

The morphology of the MAF-6 films prepared in this work ranges from nearly continuous to composed of scattered micron-sized crystallites (Figure 4d,e). For a nearly continuous MAF-6 film, high-resolution cross-sectional SEM images reveal the presence of residual $\mathrm{ZnO}$ underneath. For scattered 
micron-sized crystallites on the surface, energy-dispersive X-ray spectroscopy (EDS) reveals no residual $\mathrm{Zn}$ near the crystallites (Figures S13.1 and S13.2). These results point to fast crystallite ripening once all of the $\mathrm{ZnO}$ is consumed, aided by micron-range migration of $\mathrm{Zn}$ species on the surface. Starting from thinner $\mathrm{ZnO}$ layers results in faster $\mathrm{ZnO}$ depletion and earlier crystallite ripening (Figure S14.1). Stopping the process when all $\mathrm{ZnO}$ is consumed and before ripening takes place is critical if continuous MAF-6 films without leftover $\mathrm{ZnO}$ are required. Moreover, MAF-6 CVD requires careful temperature control. Experiments in a tube furnace and a reaction chamber with a set temperature gradient confirmed that the $\mathrm{ZnO}$ surface needs to be cooler than the reaction chamber walls (SI, Section S15), as for ZIF-8 CVD. ${ }^{18}$ To improve control over MAF-6 film morphology, the transition from simple glass reactors to reaction chambers with a high degree of temperature control and in situ monitoring capabilities should be initiated.

Cross-sectional SEM allows film thickness determination and quantification of the volume expansion upon the $\mathrm{ZnO}$-toMAF-6 transformation. The average film thickness is obtained after image processing using Fiji. ${ }^{62}$ For example, a $\sim 90 \mathrm{~nm}$ MAF-6 film on top of $\sim 5 \mathrm{~nm}$ residual $\mathrm{ZnO}$ was observed for a partially converted $10 \mathrm{~nm} \mathrm{ZnO}$ film (Figure 4d). These values are in good agreement with the theoretical film expansion coefficient of 15 calculated from the measured ALD $\mathrm{ZnO}$ density and the crystallographic $\mathrm{Zn}^{2+}$ density of MAF-6 (SI, Section S6).

Comparative Adsorption in CVD MAF-6 and ZIF-8. The difference in pore size between MAF- 6 and ZIF- 8 was demonstrated by attempting to load both materials with a large dye molecule, 9,10-dimethylanthracene (DMA) (Figure 5). While anthracene $\left(3.08 \times 8.0 \AA^{2}\right)$ can enter the ZIF-8 framework, ${ }^{49}$ DMA $\left(5.8 \times 7.18 \AA^{2}\right)$ is too large to pass the ZIF-8 windows $(6$ rings, $d=3.4 \AA) .{ }^{47}$ To avoid the coadsorption of solvents and facilitate interpretation, DMA was loaded from the vapor phase. The identical powder colors, PXRD patterns, $\mathrm{N}_{2}$ sorption isotherms, TGA data, and fluorescence emission observed for pristine and DMA-exposed ZIF-8 confirm that DMA is excluded from ZIF-8 due to molecular sieving (Figures 5a and S16.1). Conversely, MAF-6 (8-ring windows, $d=6.8 \AA$ ) changed color from white to yellow after DMA loading. The PXRD pattern of the resulting DMA@MAF-6 shows drastically changed peak intensities when compared to pristine MAF-6 (Figure 5b). The slight deviations of the peak positions can be explained by a subtle distortion of the cubic unit cell of MAF-6 to a tetragonal cell, which is not surprising given the structural flexibility of ZIFs. ${ }^{63,64}$ Attempts to locate the guest molecules using a combination of modeling and Rietveld refinement did not succeed, suggesting a nonordered arrangement of the guest molecules (Figure S17.1). No porosity is detected by $\mathrm{N}_{2}$ physisorption in DMA@MAF-6 (Figure 5c). Nevertheless, DMA can be fully desorbed by heating at $300{ }^{\circ} \mathrm{C}$ under inert gas (Figure $5 \mathrm{~d}$ ). From the weight loss upon desorption, a DMA loading of about 36 wt\% is calculated in DMA@MAF-6, corresponding to about 11 DMA molecules per cage. In comparison, a maximum of four anthracene molecules can be loaded in ZIF-8. ${ }^{49}$ Fluorescence emission spectra of the pristine and loaded materials further confirm the presence of DMA in DMA@MAF-6 (Figure S16.1). The inclusion of large molecules such as DMA in MAF-6 highlights the great potential of this material as a platform for host-guest chemistry.

\section{CONCLUSIONS}

In summary, these results demonstrate a simple solvent-free route for the bulk powder synthesis and thin film deposition of the large-pore MAF- 6 framework, based on the direct reaction of a metal precursor with a vaporized ligand. MAF-6 CVD is the first example of a vapor-phase deposition of any type of large-pore crystalline network solid. The large pore size presents great potential for the adsorption of large molecules. Eventually, we expect these results will foster a further extension of MOF-CVD to other MOF chemistries.

\section{METHODS}

Solvent-Free Powder Synthesis. In a typical procedure, the solvent-free synthesis of MAF-6 powder took place as follows. Physical mixtures of $\mathrm{ZnO}$ (>99.5\%, $25 \mathrm{~nm}$, Carl Roth ROTInanoMETIC; 99.9\%, <5 $\mu \mathrm{m}$, Sigma-Aldrich) and 2-ethylimidazole (HeIm, $98 \%$, Sigma-Aldrich) were prepared with 1:4 molar ratio in glass synthesis bottles. The capped bottles were placed in a preheated oven at a temperature of $80{ }^{\circ} \mathrm{C}$ for typically $2 \mathrm{~h}$. Afterward, the bottle was removed from the oven, immediately opened, and left to cool to room temperature in air. For selected experiments, the conversion time and temperature were varied. Activation was performed through sublimation at $150{ }^{\circ} \mathrm{C}$ under a dynamic vacuum. Activation of the EXAFS and PDF samples was achieved by wet washing using dichloromethane and ethanol to ascertain reaction quenching, followed by drying under a dynamic vacuum. For the solvent-free synthesis of ZIF-8, 2-methylimidazole (HmIm, 97\%, TCI) was used instead, and the conversion temperature was $120^{\circ} \mathrm{C}$.

ALD ZnO Film Deposition. ZnO films were deposited using a modified Savannah S-200 thermal ALD reactor (Veeco Instruments, Inc.) with deionized water and diethylzinc (97\%, STREM) as precursors. Nitrogen (99.999\%) was the carrier and purging gas used, sourced from a header line in the cleanroom facility. The pulse and purge durations for the ALD precursors were set to 0.015 and $5 \mathrm{~s}$, respectively. The reactor base pressure was $\sim 0.40 \mathrm{mbar}$ at a $\mathrm{N}_{2}$ gas flow of $20 \mathrm{sccm}$. This process resulted in a $\mathrm{ZnO}$ growth rate of $1 \AA$ cycle $^{-1}$ on $\mathrm{Si}$ substrates at $80{ }^{\circ} \mathrm{C}$. The deposited $\mathrm{ZnO}$ films are amorphous and have a density of $\sim 3.9 \mathrm{~g} \mathrm{~cm}^{-3}$ as measured by X-ray reflectivity and Rutherford backscattering spectroscopy.

MAF-6 CVD Thin Films. MAF-6 films were grown from ALD $\mathrm{ZnO}$ precursor films by placing $\mathrm{ZnO}$-coated substrates in a closed glass reactor vessel containing a powder bed of 2-ethylimidazole (HeIm) and inserting the reactor vessel in a preheated oven at 110 ${ }^{\circ} \mathrm{C}$. Typically, a temperature of $110{ }^{\circ} \mathrm{C}$ was used and a conversion time of $1 \mathrm{~h}$. Last, the samples were removed from the reactor while hot and subsequently activated at $150{ }^{\circ} \mathrm{C}$ for $30 \mathrm{~min}$. Precise control over the final film morphology could not successfully be achieved through optimization of the conversion temperature and time, as well as the background pressure and atmospheric composition in the reactor vessel, suggesting other reaction parameters to play a critical role (see also SI Section S15) and glass reactors to be insufficient with this respect.

DMA Loading in MAF-6 and ZIF-8. DMA@MAF-6 and DMAexposed ZIF-8 were prepared by postsynthetic sublimation of 9,10dimethylanthracene (DMA, 97\%, Acros Organics) into solvent-free synthesized and activated MAF- 6 and ZIF-8, respectively. Vials containing excess DMA, MAF-6, and ZIF- 8 powders were placed together in a Schlenk tube. After evacuation, the tube under static vacuum was placed in an oven $\left(120^{\circ} \mathrm{C}\right)$ for $24 \mathrm{~h}$. The samples were characterized as removed from the tube.

X-ray Diffraction (XRD). Powder X-ray diffraction (PXRD) patterns were collected on a Malvern PANalytical Empyrean diffractometer (in transmission mode) over a $1.3-45^{\circ} 2 \theta$ range, using a PIXcel3D solid-state detector and $\mathrm{Cu}$ anode $\left(\mathrm{Cu} \mathrm{K} \alpha_{1}: 1.5406\right.$ $\AA ̊$; $\mathrm{Cu} \mathrm{K \alpha} \alpha_{2}: 1.5444 \AA$ ). In situ time- and temperature-dependent 
PXRD was measured at the beamline ID10 at the European Synchrotron Radiation Facility (ESRF), Grenoble, France, using a wavelength of $1.54 \AA$ and a Pilatus $300 \mathrm{~K}$ detector mounted on a goniometer arm approximately $335 \mathrm{~mm}$ from the sample. A freshly prepared physical mixture of $\mathrm{ZnO} / \mathrm{HeIm}$ in $1: 4$ ratio was manually ground and filled in a capillary. The sealed capillary was inserted in a custom metallic capillary holder placed on the flat surface of the general-purpose heating element of the beamline. The capillary was heated at a rate of ca. $6-7{ }^{\circ} \mathrm{C} \min ^{-1}$ to $100{ }^{\circ} \mathrm{C}$ and then kept isothermally at $100{ }^{\circ} \mathrm{C}$. High-resolution synchrotron powder diffraction data for structure refinement were collected using beamline 11-BM at the Advanced Photon Source (APS), Argonne National Laboratory, using an average wavelength of $0.412703 \AA$. Discrete detectors covering an angular range from -6 to $16^{\circ} 2 \theta$ are scanned over a $34^{\circ} 2 \theta$ range, with data points collected every $0.001^{\circ} 2 \theta$ and a scan speed of $0.01^{\circ} \mathrm{s}^{-1}$. Details of the Rietveld refinement are given in SI Section S3. Grazing incidence X-ray diffraction (GIXRD) measurements were performed at the XRD1 beamline at the Elettra synchrotron, Trieste, Italy, using a stationary Pilatus $2 \mathrm{M}$ detector approximately $150 \mathrm{~mm}$ from the sample. Data were collected with a wavelength of $1.4 \AA$ and an incident angle of approximately $0.2^{\circ}$. All GIXRD and in situ PXRD data conversion (from pixel patterns to reciprocal space maps), treatment, and analysis steps were performed with GIDVis. $^{65}$

Scanning Electron Microscopy (SEM). Top-view SEM images were recorded using a Philips XL30 FEG. The samples were cleaved and then sputter-coated with $5 \mathrm{~nm}$ of $\mathrm{Pt}$ prior to the inspection. Cross-sectional view SEM images were recorded with a Hitachi SU8000 microscope (SE detector) operating at an accelerating voltage of $10 \mathrm{kV}$. The samples were sputter-coated with $1 \mathrm{~nm} \mathrm{Pt}$ (Cressington 108) and then cleaved prior to the inspection. The average film thickness was calculated over a film width of $8 \mu \mathrm{m}$ using the image processing software Fiji. ${ }^{62}$

Energy-Dispersive X-ray Spectroscopy (EDS). EDS data were measured using a Philips XL30 FEG scanning electron microscope at an electron energy of $20 \mathrm{keV}$ after sputtering the sample with carbon.

Attenuated Total Reflectance-Fourier-Transform Infrared Spectroscopy (ATR-FTIR). ATR-FTIR spectra of powder samples or films deposited on Au-coated Si wafers were recorded on a Varian 670 FTIR spectrometer coupled to a Varian 620 infrared microscope equipped with a slide-on $60^{\circ}$ Ge ATR tip and MCT detector. Sixtyfour scans were accumulated with a resolution of $4 \mathrm{~cm}^{-1}$.

Gas Physisorption. Both $\mathrm{N}_{2}$ and $\mathrm{Kr}$ sorption isotherms were measured at $-196^{\circ} \mathrm{C}(77 \mathrm{~K})$ using a Micromeritics 3Flex 3500 gas physisorption instrument. The powder samples for $\mathrm{N}_{2}$ sorption were degassed before measurements at $150{ }^{\circ} \mathrm{C}$ under vacuum $\left(10^{-2} \mathrm{mbar}\right)$ for $4 \mathrm{~h}$. The BET method was applied in the region between 0.005 and $0.05 \mathrm{P} / \mathrm{P}_{0}$, consistent with the consistency criteria for microporous materials. ${ }^{66}$ The pore size distribution was calculated from the adsorption branch using a density functional theory model (cylindrical pore geometry, oxide surface). Krypton physisorption measurements on films have been performed according to previous works. ${ }^{17,67}$ The samples were degassed before measurement at $150{ }^{\circ} \mathrm{C}$ under vacuum $\left(10^{-2} \mathrm{mbar}\right)$ for $1 \mathrm{~h}$. Gas uptake equilibria were measured between $10^{-5}$ and 2.15 mbar (deposition saturation pressure, $\left.P_{0, \text { solid }}\right)$.

Fluorescence Measurements. Fluorescence emission maps were recorded on a FLS 920 fluorescence spectrophotometer (Edinburgh Instruments, Photonic division).

Thermogravimetric Analysis (TGA). All thermogravimetric analyses were performed using a Netzsch STA 449 F3 Jupiter. Decomposition experiments were carried out in air between room temperature and 600 or $800{ }^{\circ} \mathrm{C}$ with a constant heating rate of $5{ }^{\circ} \mathrm{C}$ $\mathrm{min}^{-1}$. Thermal desorption of DMA adsorbed in MAF- 6 was carried out under a nitrogen atmosphere by heating the sample with a constant rate of $3{ }^{\circ} \mathrm{C} \mathrm{min}{ }^{-1}$ to $300{ }^{\circ} \mathrm{C}$ followed by an isothermal step.

Total Scattering Measurements. X-ray data were collected at the I15-1 beamline $(\lambda=0.161669 \AA, 76.7 \mathrm{keV})$ at the Diamond Light Source, Oxfordshire, U.K.. Powder samples were loaded into borosilicate glass capillaries of $1.50 \mathrm{~mm}$ (inner) diameter and wax- sealed. Data on the samples, empty instrument, and capillary were collected in the region of $\sim 0.4<Q<\sim 31 \AA^{-1}$. Corrections for background, multiple scattering, capillary scattering, Compton scattering, and adsorption were performed using GudrunX software. ${ }^{68}$ In situ nonambient measurements were performed using an identical setup, with borosilicate capillaries loaded with a physical mixture of $\mathrm{ZnO}$ and HeIm powders and sealed with Araldite. Data on ex situ prepared samples and references ( $\mathrm{ZnO}$, HeIm, MAF-6) were collected at a room temperature of $25^{\circ} \mathrm{C}$, while in situ measurements were carried out upon sample heating to 80 and $100{ }^{\circ} \mathrm{C}$. Data refinement was performed with PDFgui software ${ }^{69}$ using reported or refined structure files for $\mathrm{ZnO}$, MAF-6, and HeIm structural models. Isotropic displacement parameters, $U_{11}, U_{22}$ and $U_{33}$, were set to $0.003 \AA^{2}$ for all models, while cross-diagonal terms were set to 0. All fits were performed for the range $1 \AA<r<30 \AA$ to fully encompass the MAF-6 unit cell (29.2944 $\AA$ ).

Extended X-ray Absorption Fine Structure (EXAFS). X-ray absorption measurements of $\mathrm{Zn} k$-edge were carried out at the DutchBelgian (DUBBLE) BM26 beamline at the European Synchrotron Radiation Facility (ESRF), Grenoble, France. Measurements were performed in transmission mode. The beamline consists of a $\mathrm{Rh} / \mathrm{Pt}$ coated meridional cylindrical mirror for collimation and a $\mathrm{Si}(111) /$ $\mathrm{Si}(333)$-based double crystal monochromator to select excitation energy. The energy range of XAFS was calibrated using a reference $\mathrm{Zn}$ foil at $9659 \mathrm{eV}$. The EXAFS data have been examined using FEFF $6.0{ }^{70}$ comprising Fourier-transform with background reduction to derive the versus $R$ spectra from the absorption spectra in ATHENA software. ${ }^{71}$ Theoretical EXAFS spectra, starting from crystallographic structural models, were generated, and fitting of the experimental data with the theoretical spectra was performed in ARTEMIS software. ${ }^{71}$

Positron Annihilation Lifetime Spectroscopy (PALS). PALS measurements were executed at the pulsed low energy positron beam system (PLEPS), operated at the neutron-induced positron source Munich (NEPOMUC).$^{72-74}$ The film and powder were measured at 1 and $1.5 \mathrm{keV}$, corresponding to, respectively, mean implantation depths of ca. 40 and $78 \mathrm{~nm},{ }^{73}$ for a MAF-6 density of $0.77 \mathrm{~g} \mathrm{~cm}^{-3}$ (calculated crystallographic density). For the PALS spectra, 4 million counts were collected with a count rate of ca. $10000 \mathrm{cts} \mathrm{s}^{-1}$ and a time resolution of ca. 250 ps. All spectra were evaluated with POSWIN and PALSfit $3 .^{76}$ The resolution function was determined by measuring p-doped $\mathrm{SiC}$, a sample with known lifetimes. All spectra were deconvoluted into four lifetime components ( $p$-Ps, free $\mathrm{e}+$, and two $o$-Ps) with good overall fit variances from 1.0 to 1.1 .

1H NMR Spectroscopy. Quantitative ${ }^{1} \mathrm{H}$ NMR data were obtained using a Bruker Avance III HD 400 after digestion of activated samples in a $\mathrm{D}_{2} \mathrm{O} / \mathrm{D}_{2} \mathrm{SO}_{4}$ solution with tetramethylammonium bromide (TMAB) as standard.

Simulations. Molecular models of the anthracene and 9,10dimethylanthracene were constructed using Materials Studio. ${ }^{77}$ The constructed structural models were further optimized using the software provided Forcite module with the COMPASS force field. All calculations were performed with the highest degree of quality with spatial displacement resolution of $0.05 \AA$ while resorting to 5000 iterations/movement. Molecular dimensions were determined for the optimized structural models. The surface area of MAF-6 was calculated using Materials Studio after adding protons and assuming a spherical guest molecule with the kinetic diameter of nitrogen (3.64 $\AA$ ).

\section{ASSOCIATED CONTENT}

\section{Supporting Information}

The Supporting Information is available free of charge at https://pubs.acs.org/doi/10.1021/acs.chemmater.9b03807.

Powder synthesis at room conditions and MOF activation; XRD data and structure refinement; ${ }^{1} \mathrm{H}$ NMR spectrum and calculations; SEM images; volume expansion calculations and coefficients; $\mathrm{N}_{2}$ physisorption data; EXAFS data; total scattering data; ATR-FTIR 
spectra; PALS data and implantation profiles; EDS data; fluorescence emission spectra (PDF)

\section{AUTHOR INFORMATION}

\section{Corresponding Author}

Rob Ameloot - Centre for Membrane Separations, Adsorption, Catalysis and Spectroscopy for Sustainable Solutions (cMACS), KU Leuven, 3001 Leuven, Belgium; 다이.org/0000-00033178-5480; Phone: +32 163766 74; Email: rob.ameloot@ kuleuven.be

\section{Authors}

Timothée Stassin - Centre for Membrane Separations, Adsorption, Catalysis and Spectroscopy for Sustainable Solutions (cMACS), KU Leuven, 3001 Leuven, Belgium; (1) orcid.org/0000-0002-1175-4057

Ivo Stassen - Centre for Membrane Separations, Adsorption, Catalysis and Spectroscopy for Sustainable Solutions (cMACS), KU Leuven, 3001 Leuven, Belgium

João Marreiros - Centre for Membrane Separations, Adsorption, Catalysis and Spectroscopy for Sustainable Solutions (cMACS), KU Leuven, 3001 Leuven, Belgium; 다이.org/0000-00024898-2096

Alexander John Cruz - Centre for Membrane Separations, Adsorption, Catalysis and Spectroscopy for Sustainable Solutions (cMACS), KU Leuven, 3001 Leuven, Belgium; (1) orcid.org/0000-0002-5123-1162

Rhea Verbeke - Centre for Membrane Separations, Adsorption, Catalysis and Spectroscopy for Sustainable Solutions (cMACS), KU Leuven, 3001 Leuven, Belgium

Min Tu - Centre for Membrane Separations, Adsorption, Catalysis and Spectroscopy for Sustainable Solutions (cMACS), KU Leuven, 3001 Leuven, Belgium

Helge Reinsch - Institut für Anorganische Chemie, ChristianAlbrechts-Universität zu Kiel, 24118 Kiel, Germany; () orcid.org/0000-0001-5288-1135

Marcel Dickmann - Heinz Maier-Leibnitz Zentrum (MLZ) and Physik Department E21, Technische Universität München, 85748 Garching, Germany

Werner Egger - Institut fur Angewandte Physik und Messtechnik LRT2, Universität der Bundeswehr München, 85577 Neubiberg, Germany

Ivo F. J. Vankelecom - Centre for Membrane Separations, Adsorption, Catalysis and Spectroscopy for Sustainable Solutions (cMACS), KU Leuven, 3001 Leuven, Belgium

Dirk E. De Vos - Centre for Membrane Separations, Adsorption, Catalysis and Spectroscopy for Sustainable Solutions (cMACS), KU Leuven, 3001 Leuven, Belgium

Complete contact information is available at:

https://pubs.acs.org/10.1021/acs.chemmater.9b03807

\section{Author Contributions}

The manuscript was written through the contributions of all authors. All authors have given approval to the final version of the manuscript.

\section{Notes}

The authors declare no competing financial interest. CCDC-1953282 contains the supplementary crystallographic data for this paper.

\section{ACKNOWLEDGMENTS}

T.S., R.V., and I.S. thank the Research Foundation Flanders (FWO) for SB-PhD and postdoctoral fellowships (1S53316N, $1500917 \mathrm{~N}$, and $12 \mathrm{~L} 5417 \mathrm{~N}$ ). R.A. acknowledges the funding from the European Research Council (no. 716472, acronym: VAPORE), from the European Union's Horizon 2020 FETOPEN-1-2016-2017 research and innovation programme under grant agreement 801464, and from the Research Foundation Flanders (FWO) in the research projects G083016N, G0E6319N, and $1501618 \mathrm{~N}$, and in the infrastructure project G0H0716N. We acknowledge the Elettra Synchrotron Trieste for allocation of beam time (proposal 20180092) and thank Luisa Barba and Nicola Demitri for assistance in using beamline XRD1. We acknowledge the European Synchrotron Radiation Facility for provision of synchrotron radiation facilities (experiments MA-4411 and 2601-1126), and we would like to thank Oleg Konovalov and Andrey Chumakov for assistance in using beamline ID10 and Dipanjan Banerjee for assistance in using the Dutch-Belgian (DUBBLE) beamline BM26. We acknowledge Benedikt Schrode and Sabina Rodriguez Hermida for assistance with the in situ PXRD experiment and data processing. PALS measurements are based upon experiments performed at the PLEPS instrument operated by FRM-II at the Heinz MaierLeibnitz Zentrum (MLZ), Garching, Germany. The authors would like to thank Diamond Light Source for beam time (proposal EE17279), and the staff of beamline I15-1, in particular Philip Chater, with data collection and treatment. Thomas D. Bennett is acknowledged for useful insights in total scattering data processing and analysis. Use of the Advanced Photon Source at Argonne National Laboratory was supported by the U. S. Department of Energy, Office of Science, Office of Basic Energy Sciences, under Contract No. DE-AC0206CH11357.

\section{ABBREVIATIONS}

MOF, metal-organic framework; ZIF, zeolitic imidazolate framework; MAF, metal-azolate framework; CVD, chemical vapor deposition; HmIm, 2-methylimidazole; HeIm, 2-ethylimidazole; (I)LAG, (ion-) and liquid-assisted grinding; (P/ GI)XRD, (powder/grazing incidence) X-ray diffraction; TGA, thermogravimetric analysis; NMR, nuclear magnetic resonance; SEM, scanning electron microscopy; PALS, positron annihilation lifetime spectroscopy; EDS, energy-dispersive $\mathrm{X}$ ray spectroscopy; DMA, 9,10-dimethylanthracene; PDF, pair distribution function; (FT-)EXAFS, (Fourier-transform) extended X-ray absorption fine structure

\section{REFERENCES}

(1) Furukawa, H.; Cordova, K. E.; O’Keeffe, M.; Yaghi, O. M. The Chemistry and Applications of Metal-Organic Frameworks. Science 2013, 341, No. 1230444.

(2) Hönicke, I. M.; Senkovska, I.; Bon, V.; Baburin, I. A.; Bönisch, N.; Raschke, S.; Evans, J. D.; Kaskel, S. Balancing Mechanical Stability and Ultrahigh Porosity in Crystalline Framework Materials. Angew. Chem., Int. Ed. 2018, 57, 13780-13783.

(3) Corma, A.; García, H.; Llabrés i Xamena, F. X. Engineering Metal Organic Frameworks for Heterogeneous Catalysis. Chem. Rev. 2010, 110, 4606-4655.

(4) Li, J.-R.; Kuppler, R. J.; Zhou, H.-C. Selective Gas Adsorption and Separation in Metal-organic Frameworks. Chem. Soc. Rev. 2009, $38,1477-1504$.

(5) Stassen, I.; Burtch, N.; Talin, A.; Falcaro, P.; Allendorf, M.; Ameloot, R. An Updated Roadmap for the Integration of Metal- 
organic Frameworks with Electronic Devices and Chemical Sensors. Chem. Soc. Rev. 2017, 46, 3185-3241.

(6) Rubio-Martinez, M.; Avci-Camur, C.; Thornton, A. W.; Imaz, I.; Maspoch, D.; Hill, M. R. New Synthetic Routes towards MOF Production at Scale. Chem. Soc. Rev. 2017, 46, 3453-3480.

(7) Julien, P. A.; Mottillo, C.; Friščić, T. Metal-organic Frameworks Meet Scalable and Sustainable Synthesis. Green Chem. 2017, 19, 2729-2747.

(8) James, S. L.; Adams, C. J.; Bolm, C.; Braga, D.; Collier, P.; Friščić, T.; Grepioni, F.; Harris, K. D. M.; Hyett, G.; Jones, W.; et al. Mechanochemistry: Opportunities for New and Cleaner Synthesis. Chem. Soc. Rev. 2012, 41, 413-447.

(9) Mottillo, C.; Frišcić, T. Advances in Solid-State Transformations of Coordination Bonds: From the Ball Mill to the Aging Chamber. Molecules 2017, 22, No. 144.

(10) Lin, J.-B.; Lin, R.-B.; Cheng, X.-N.; Zhang, J.-P.; Chen, X.-M. Solvent/Additive-Free Synthesis of Porous/Zeolitic Metal Azolate Frameworks from Metal Oxide/Hydroxide. Chem. Commun. 2011, 47, 9185-9187.

(11) Lanchas, M.; Vallejo-Sánchez, D.; Beobide, G.; Castillo, O.; Aguayo, A. T.; Luque, A.; Román, P. A Direct Reaction Approach for the Synthesis of Zeolitic Imidazolate Frameworks: Template and Temperature Mediated Control on Network Topology and Crystal Size. Chem. Commun. 2012, 48, 9930-9932.

(12) Cliffe, M. J.; Mottillo, C.; Stein, R. S.; Bučar, D.-K.; Frǐ̌čić, T. Accelerated Aging: A Low Energy, Solvent-Free Alternative to Solvothermal and Mechanochemical Synthesis of Metal-organic Materials. Chem. Sci. 2012, 3, 2495-2500.

(13) Mottillo, C.; Lu, Y.; Pham, M.-H.; Cliffe, M. J.; Do, T.-O.; Friščić, T. Mineral Neogenesis as an Inspiration for Mild, SolventFree Synthesis of Bulk Microporous Metal-organic Frameworks from Metal (Zn, Co) Oxides. Green Chem. 2013, 15, 2121-2131.

(14) Tanaka, S.; Kida, K.; Nagaoka, T.; Ota, T.; Miyake, Y. Mechanochemical Dry Conversion of Zinc Oxide to Zeolitic Imidazolate Framework. Chem. Commun. 2013, 49, 7884-7886.

(15) Frameworks for Commercial Success. Nat. Chem. 2016, 8987. DOI: $10.1038 /$ nchem. 2661 .

(16) Handbook of Thin-Film Deposition Processes and Techniques: Principles, Methods, Equipment and Applications; Seshan, K., Ed.; Noyes Publications/William Andrew Pub: Norwich, N.Y, 2002.

(17) Stassen, I.; Styles, M.; Grenci, G.; Gorp, H. V.; Vanderlinden, W.; Feyter, S. D.; Falcaro, P.; Vos, D. D.; Vereecken, P.; Ameloot, R. Chemical Vapour Deposition of Zeolitic Imidazolate Framework Thin Films. Nat. Mater. 2016, 15, 304-310.

(18) Cruz, A. J.; Stassen, I.; Krishtab, M.; Marcoen, K.; Stassin, T.; Rodríguez-Hermida, S.; Teyssandier, J.; Pletincx, S.; Verbeke, R.; Rubio-Giménez, V.; et al. An Integrated Cleanroom Process for the Vapor-Phase Deposition of Large-Area Zeolitic Imidazolate Framework Thin Films. Chem. Mater. 2019, DOI: 10.1021/acs.chemmater.9b03435.

(19) Khaletskaya, K.; Turner, S.; Tu, M.; Wannapaiboon, S.; Schneemann, A.; Meyer, R.; Ludwig, A.; Van Tendeloo, G.; Fischer, R. A. Self-Directed Localization of ZIF-8 Thin Film Formation by Conversion of $\mathrm{ZnO}$ Nanolayers. Adv. Funct. Mater. 2014, 24, 48044811.

(20) Stassen, I.; De Vos, D.; Ameloot, R. Vapor-Phase Deposition and Modification of Metal-Organic Frameworks: State-of-the-Art and Future Directions. Chem. - Eur. J. 2016, 22, 14452-14460.

(21) Krishtab, M.; Stassen, I.; Stassin, T.; Cruz, A. J.; Okudur, O. O.; Armini, S.; Wilson, C.; Gendt, S. D.; Ameloot, R. Vapor-Deposited Zeolitic Imidazolate Frameworks as Gap-Filling Ultra-Low-k Dielectrics. Nat. Commun. 2019, 10, No. 3729.

(22) Stassin, T.; Rodríguez-Hemida, S.; Schrode, B.; Cruz, A. J.; Carraro, F.; Kravchenko, D.; Creemers, V.; Stassen, I.; Hauffman, T.; Vos, D. E. D.; et al. Vapour-Phase Deposition of Oriented Copper Dicarboxylate Metal-Organic Framework Thin Films. Chem. Commun. 2019, 55, 10056-10059.
(23) Han, S.; Ciufo, R. A.; Meyerson, M. L.; Keitz, B. K.; Mullins, C. B. Solvent-Free Vacuum Growth of Oriented HKUST-1 Thin Films. J. Mater. Chem. A 2019, 7, 19396-19406.

(24) Medishetty, R.; Zhang, Z.; Sadlo, A.; Cwik, S.; Peeters, D.; Henke, S.; Mangayarkarasi, N.; Devi, A. Fabrication of ZincDicarboxylate- and Zinc-Pyrazolate-Carboxylate-Framework Thin Films through Vapour-solid Deposition. Dalton Trans. 2018, 47, 14179-14183.

(25) Salmi, L. D.; Heikkilä, M. J.; Puukilainen, E.; Sajavaara, T.; Grosso, D.; Ritala, M. Studies on Atomic Layer Deposition of MOF-5 Thin Films. Microporous Mesoporous Mater. 2013, 182, 147-154.

(26) Salmi, L. D.; Heikkilä, M. J.; Vehkamäki, M.; Puukilainen, E.; Ritala, M.; Sajavaara, T. Studies on Atomic Layer Deposition of IRMOF-8 Thin Films. J. Vacuum Sci. Technol. A 2014, 33, No. 01A121.

(27) Lausund, K. B.; Nilsen, O. All-Gas-Phase Synthesis of UiO-66 through Modulated Atomic Layer Deposition. Nat. Commun. 2016, 7, No. 13578.

(28) Lausund, K. B.; Petrovic, V.; Nilsen, O. All-Gas-Phase Synthesis of Amino-Functionalized UiO-66 Thin Films. Dalton Trans. 2017, 46, 16983-16992.

(29) Stassin, T.; Stassen, I.; Wauteraerts, N.; Cruz, A. J.; Kräuter, M.; Coclite, A. M.; Vos, D. D.; Ameloot, R. Solvent-Free Powder Synthesis and Thin Film Chemical Vapour Deposition of a Zinc Bipyridyl-Triazolate Framework. Eur. J. Inorg. Chem. 2020, 1, 71-74.

(30) Ahvenniemi, E.; Karppinen, M. In Situ Atomic/Molecular Layer-by-Layer Deposition of Inorganic-Organic Coordination Network Thin Films from Gaseous Precursors. Chem. Mater. 2016, $28,6260-6265$.

(31) Ahvenniemi, E.; Karppinen, M. Atomic/Molecular Layer Deposition: A Direct Gas-Phase Route to Crystalline Metal-organic Framework Thin Films. Chem. Commun. 2016, 52, 1139-1142.

(32) Xu, P.; Liu, M.; Li, X.; Xu, T.; Zhang, Y. In Multi-Dimensional Multi-Level Sensing Nanostructure for High-Performance Detection to Trace-Level Dopamine Molecules, 19th International Conference on Solid-State Sensors, Actuators and Microsystems (Transducers), 2017; pp 762-765.

(33) Amer, W. A.; Wang, J.; Ding, B.; Li, T.; Allah, A. E.; Zakaria, M. B.; Henzie, J.; Yamauchi, Y. Physical Expansion of Layered Graphene Oxide Nanosheets Using MOF-CVD and Their Thermal Conversion into Nitrogen-Doped Porous Carbons for Supercapacitor Applications. ChemSusChem 2019, 12, 1-9.

(34) Li, Y.; Xie, H.; Li, J.; Bando, Y.; Yamauchi, Y.; Henzie, J. High Performance Nanoporous Carbon Microsupercapacitors Generated by a Solvent-Free MOF-CVD Method. Carbon 2019, 152, 688-696.

(35) Li, W.; Su, P.; Li, Z.; Xu, Z.; Wang, F.; Ou, H.; Zhang, J.; Zhang, G.; Zeng, E. Ultrathin Metal-organic Framework Membrane Production by Gel-vapour Deposition. Nat. Commun. 2017, 8, No. 406.

(36) Paknameh, N.; Fatemi, S.; Razavian, M. EPD Method of Seeding Nano ZnO Followed by CVD of Organo-Linker; a Step by Step Method for Synthesis of ZIF-8 Thin Layer on Tubular $\alpha$ Alumina. Mater. Chem. Phys. 2019, 235, No. 121764.

(37) Huang, X.-C.; Lin, Y.-Y.; Zhang, J.-P.; Chen, X.-M. LigandDirected Strategy for Zeolite-Type Metal-Organic Frameworks: Zinc(II) Imidazolates with Unusual Zeolitic Topologies. Angew. Chem., Int. Ed. 2006, 45, 1557-1559.

(38) Baerlocher, C.; McCusker, L. B.; Olson, D. H. Atlas of Zeolite Framework Types, 6th revised ed.; Elsevier: Amsterdam, 2007.

(39) Evtushenko, Y. M.; Zaitsev, B. E.; Ivanov, V. M.; Gitis, K. M. 2Methylimidazole as a Reagent for the Photometric Determination of Maleic Anhydride. J. Anal. Chem. 2000, 55, 142-145.

(40) Jiménez, P.; Roux, M. V.; Turrión, C. Thermochemical Properties of N-Heterocyclic Compounds IV. Enthalpies of Combustion, Vapour Pressures and Enthalpies of Sublimation, and Enthalpies of Formation of 2-Methylimidazole and 2-Ethylimidazole. J. Chem. Thermodyn. 1992, 24, 1145-1149.

(41) He, C.-T.; Jiang, L.; Ye, Z.-M.; Krishna, R.; Zhong, Z.-S.; Liao, P.-Q.; Xu, J.; Ouyang, G.; Zhang, J.-P.; Chen, X.-M. Exceptional 
Hydrophobicity of a Large-Pore Metal-Organic Zeolite. J. Am. Chem. Soc. 2015, 137, 7217-7223.

(42) Beldon, P. J.; Fábián, L.; Stein, R. S.; Thirumurugan, A.; Cheetham, A. K.; Friščić, T. Rapid Room-Temperature Synthesis of Zeolitic Imidazolate Frameworks by Using Mechanochemistry. Angew. Chem., Int. Ed. 2010, 49, 9640-9643.

(43) Friščćć, T.; Halasz, I.; Beldon, P. J.; Belenguer, A. M.; Adams, F.; Kimber, S. A. J.; Honkimäki, V.; Dinnebier, R. E. Real-Time and in Situ Monitoring of Mechanochemical Milling Reactions. Nat. Chem. 2013, 5, 66-73.

(44) Bhadra, B. N.; Seo, P. W.; Khan, N. A.; Jhung, S. H. Hydrophobic Cobalt-Ethylimidazolate Frameworks: Phase-Pure Syntheses and Possible Application in Cleaning of Contaminated Water. Inorg. Chem. 2016, 55, 11362-11371.

(45) López-Cabrelles, J.; Romero, J.; Abellán, G.; Giménez-Marqués, M.; Palomino, M.; Valencia, S.; Rey, F.; Mínguez Espallargas, G. Solvent-Free Synthesis of ZIFs: A Route toward the Elusive Fe(II) Analogue of ZIF-8. J. Am. Chem. Soc. 2019, 141, 7173-7180.

(46) Stassen, I.; Campagnol, N.; Fransaer, J.; Vereecken, P.; Vos, D. D.; Ameloot, R. Solvent-Free Synthesis of Supported ZIF-8 Films and Patterns through Transformation of Deposited Zinc Oxide Precursors. CrystEngComm 2013, 15, 9308-9311.

(47) Park, K. S.; Ni, Z.; Cote, A. P.; Choi, J. Y.; Huang, R.; UribeRomo, F. J.; Chae, H. K.; O’Keeffe, M.; Yaghi, O. M. Exceptional Chemical and Thermal Stability of Zeolitic Imidazolate Frameworks. Proc. Natl. Acad. Sci. 2006, 103, 10186-10191.

(48) Thommes, M.; Kaneko, K.; Neimark, A. V.; Olivier, J. P.; Rodriguez-Reinoso, F.; Rouquerol, J.; Sing, K. S. W. Physisorption of Gases, with Special Reference to the Evaluation of Surface Area and Pore Size Distribution (IUPAC Technical Report). Pure Appl. Chem. 2015, 87, 1051-1069.

(49) Tu, M.; Reinsch, H.; Rodríguez-Hermida, S.; Verbeke, R.; Stassin, T.; Egger, W.; Dickmann, M.; Dieu, B.; Hofkens, J.; Vankelecom, I. F. J.; et al. Reversible Optical Writing and Data Storage in an Anthracene-Loaded Metal-Organic Framework. Angew. Chem., Int. Ed. 2019, 58, 2423-2427.

(50) Hafizovic, J.; Bjørgen, M.; Olsbye, U.; Dietzel, P. D. C.; Bordiga, S.; Prestipino, C.; Lamberti, C.; Lillerud, K. P. The Inconsistency in Adsorption Properties and Powder XRD Data of MOF-5 Is Rationalized by Framework Interpenetration and the Presence of Organic and Inorganic Species in the Nanocavities. J. Am. Chem. Soc. 2007, 129, 3612-3620.

(51) Esken, D.; Noei, H.; Wang, Y.; Wiktor, C.; Turner, S.; Tendeloo, G. V.; Fischer, R. A. ZnO@ZIF-8: Stabilization of Quantum Confined ZnO Nanoparticles by a Zinc Methylimidazolate Framework and Their Surface Structural Characterization Probed by CO2 Adsorption. J. Mater. Chem. 2011, 21, 5907-5915.

(52) Borsboom, M.; Bras, W.; Cerjak, I.; Detollenaere, D.; Glastra van Loon, D.; Goedtkindt, P.; Konijnenburg, M.; Lassing, P.; Levine, Y. K.; Munneke, B.; et al. The Dutch-Belgian Beamline at the ESRF. J Synchrotron Radiat. 1998, 5, 518-520.

(53) Midya, N.; Neogi, S. K.; Ahmed, M. A.; Banerjee, A.; Kumar, P.; Kanjilal, D.; Bandyopadhyay, S. Correlation between Magnetic and Micro-Structural Properties of Low Energy Ion Irradiated and UnIrradiated $\mathrm{Zn}{ }_{0.95} \mathrm{Mn}_{0.05}$ O Films. RSC Adv. 2017, 7, 771-781.

(54) Rana, A. K.; Kumar, Y.; Rajput, P.; Jha, S. N.; Bhattacharyya, D.; Shirage, P. M. Search for Origin of Room Temperature Ferromagnetism Properties in Ni-Doped $\mathrm{ZnO}$ Nanostructure. ACS Appl. Mater. Interfaces 2017, 9, 7691-7700.

(55) Terban, M. W.; Banerjee, D.; Ghose, S.; Medasani, B.; Shukla, A.; Legg, B. A.; Zhou, Y.; Zhu, Z.; Sushko, M. L.; Yoreo, J. J. D.; et al. Early Stage Structural Development of Prototypical Zeolitic Imidazolate Framework (ZIF) in Solution. Nanoscale 2018, 10, 4291-4300.

(56) Farrow, C. L.; Juhas, P.; Liu, J. W.; Bryndin, D.; Božin, E. S.; Bloch, J.; Proffen, T.; Billinge, S. J. L. PDFfit2 and PDFgui: Computer Programs for Studying Nanostructure in Crystals. J. Phys. B: Condens. Matter 2007, 19, No. 335219.
(57) Hughes, J. T.; Bennett, T. D.; Cheetham, A. K.; Navrotsky, A. Thermochemistry of Zeolitic Imidazolate Frameworks of Varying Porosity. J. Am. Chem. Soc. 2013, 135, 598-601.

(58) Mogensen, O. E. Positron Annihilation in Chemistry; Springer: Berlin, Heidelberg, 1995.

(59) Tao, S. J. Positronium in Molecular Substances. Appl. Phys. 1974, 3, 1-7.

(60) Eldrup, M. M.; Lightbody, D.; Sherwood, J. N. The Temperature Dependence of Positron Lifetimes in Solid Pivalic Acid. Chem. Phys. 1981, 63, 51-58.

(61) Willems, T. F.; Rycroft, C. H.; Kazi, M.; Meza, J. C.; Haranczyk, M. Algorithms and Tools for High-Throughput Geometry-Based Analysis of Crystalline Porous Materials. Microporous Mesoporous Mater. 2012, 149, 134-141.

(62) Schindelin, J.; Arganda-Carreras, I.; Frise, E.; Kaynig, V.; Longair, M.; Pietzsch, T.; Preibisch, S.; Rueden, C.; Saalfeld, S.; Schmid, B.; et al. Fiji: An Open-Source Platform for Biological-Image Analysis. Nat. Methods 2012, 9, 676-682.

(63) Cai, W.; Lee, T.; Lee, M.; Cho, W.; Han, D.-Y.; Choi, N.; Yip, A. C. K.; Choi, J. Thermal Structural Transitions and Carbon Dioxide Adsorption Properties of Zeolitic Imidazolate Framework-7 (ZIF-7). J. Am. Chem. Soc. 2014, 136, 7961-7971.

(64) Fairen-Jimenez, D.; Moggach, S. A.; Wharmby, M. T.; Wright, P. A.; Parsons, S.; Düren, T. Opening the Gate: Framework Flexibility in ZIF-8 Explored by Experiments and Simulations. J. Am. Chem. Soc. 2011, 133, 8900-8902.

(65) Schrode, B.; Pachmajer, S.; Dohr, M.; Röthel, C.; Domke, J.; Fritz, T.; Resel, R.; Werzer, O. GIDVis: A Comprehensive Software Tool for Geometry-Independent Grazing-Incidence X-Ray Diffraction Data Analysis and Pole-Figure Calculations. J. Appl. Crystallogr. 2019, $52,683-689$.

(66) Rouquerol, J.; Llewellyn, P.; Rouquerol, F. Is the BET Equation Applicable to Microporous Adsorbents? Stud. Surf. Sci. Catal. 2007, $160,49-56$.

(67) Campagnol, N.; Stassen, I.; Binnemans, K.; Vos, D. E. de.; Fransaer, J. Metal-organic Framework Deposition on Dealloyed Substrates. J. Mater. Chem. A 2015, 3, 19747-19753.

(68) Soper, A. K.; Barney, E. R. Extracting the Pair Distribution Function from White-Beam X-Ray Total Scattering Data. J. Appl. Crystallogr. 2011, 44, 714-726.

(69) Farrow, C. L.; Juhas, P.; Liu, J. W.; Bryndin, D.; Božin, E. S.; Bloch, J.; Proffen, T.; Billinge, S. J. L. PDFfit2 and PDFgui: Computer Programs for Studying Nanostructure in Crystals. J. Phys.: Condens. Matter 2007, 19, No. 335219.

(70) Zabinsky, S. I.; Rehr, J. J.; Ankudinov, A.; Albers, R. C.; Eller, M. J. Multiple-Scattering Calculations of $\mathrm{x}$-Ray-Absorption Spectra. Phys. Rev. B 1995, 52, 2995-3009.

(71) Ravel, B.; Newville, M. ATHENA, ARTEMIS, HEPHAESTUS: Data Analysis for X-Ray Absorption Spectroscopy Using IFEFFIT. $J$ Synchrotron Rad 2005, 12, 537-541.

(72) Hugenschmidt, C.; Dollinger, G.; Egger, W.; Kögel, G.; Löwe, B.; Mayer, J.; Pikart, P.; Piochacz, C.; Repper, R.; Schreckenbach, K.; et al. Surface and Bulk Investigations at the High Intensity Positron Beam Facility NEPOMUC. Appl. Surf. Sci. 2008, 255, 29-32.

(73) Hugenschmidt, C.; Piochacz, C.; Reiner, M.; Schreckenbach, K. The NEPOMUC Upgrade and Advanced Positron Beam Experiments. New J. Phys. 2012, 14, No. 055027.

(74) Sperr, P.; Egger, W.; Kögel, G.; Dollinger, G.; Hugenschmidt, C.; Repper, R.; Piochacz, C. Status of the Pulsed Low Energy Positron Beam System (PLEPS) at the Munich Research Reactor FRM-II. Appl. Surf. Sci. 2008, 255, 35-38.

(75) Algers, J.; Sperr, P.; Egger, W.; Kögel, G.; Maurer, F. H. J. Median Implantation Depth and Implantation Profile of 3-18 KeV Positrons in Amorphous Polymers. Phys. Rev. B 2003, 67, No. 125404.

(76) Kirkegaard, P.; Olsen, J. V.; Eldrup, M. M. PALSfit3: A Software Package for Analysing Positron Lifetime Spectra A Software Package for Analysing Positron Lifetime Spectra; Technical University of Denmark: Kgs Lyngby, 2017.

(77) Accelrys Software; Materials Studio, 2009. 